\title{
Strong humoral response elicited by a DNA vaccine targeting gastrin-releasing peptide with optimized adjuvants inhibits murine prostate carcinoma growth in vivo
}

\author{
Yong $\mathrm{Lu}^{1,2}$, Didier $\mathrm{J} \mathrm{L} \mathrm{Mekoo}^{1}$, Kedong Ouyang ${ }^{1}$, Xiangbing $\mathrm{Hu}^{1}$, Yanhua $\mathrm{Liu}^{1}$, \\ Ming Lin ${ }^{1}$, 'Liang Jin ${ }^{1}$, Rongyue Cao ${ }^{1}$, Taiming Li ${ }^{1}$, Yankai Zhang ${ }^{1}$, Hao Fan ${ }^{2}$ \\ and Jingjing Liu ${ }^{1}$

\footnotetext{
${ }^{1}$ Minigene Pharmacy Laboratory, Biopharmaceutical College, China Pharmaceutical University, 24 Tongjia Xiang, Nanjing 210009, People's Republic of China

${ }^{2}$ Shanghai Yijiu Biomedical Cooperation Ltd, Shanghai Zhangjiang Hi-Tech Park, Shanghai 210009, People's Republic of China

(Correspondence should be addressed to L Jingjing; Email: minigene1@21cn.com)
}

\begin{abstract}
Previous studies demonstrated that the elevated expression and receptor binding of gastrinreleasing peptide (GRP) in various types of cancer suggest that GRP might be a putative target for immunotherapy in neoplastic diseases. DNA vaccine for hormone/growth factor immune deprivation represents a feasible and attractive approach for cancer treatment; nevertheless, there is still a need to increase the potency of the DNA vaccine. Here, based on six copies of the $B$ cell epitope $\mathrm{GRP}_{18-27}$ in a linear alignment as an immunogen, we designed several anti-GRP DNA vaccines containing different combinations of immunoadjuvants, such as HSP65, tetanus toxoid $_{830-844}(\mathrm{~T})$, pan HLA-DR-binding epitope (PADRE) (P), and mycobacterial HSP70 $407-426$ (M), on a backbone of pCR3.1 plasmid vector with eight $5^{\prime}$-GACGTT-3' CpG motifs and the VEGF183 signal peptide (VS). The effects of these immunoadjuvants in enhancing GRP-specific humoral immune response were then evaluated by comparing the respective immunogenicity and antitumor effects. Immunization of mice with pCR3.1-VS-HSP65-TP-GRP6-M2 elicited much higher levels of specific anti-GRP antibodies and more effectively inhibited the growth of a GRP-dependent tumor RM-1 in vivo. Interestingly, plasmids encoding for $2 \mathrm{HSP}^{2} \mathrm{O}_{407-426}$, but not the one with 1 or $3 \mathrm{HSP}_{407-426}$ showed stronger immune stimulatory potential as well as impressive antitumor activity, suggesting that $2 \mathrm{HSP} \mathrm{O}_{407-426}$ is an efficient molecular adjuvant for developing self-epitope vaccines. The highly immunogenic, potent anti-tumorigenic and antiangiogenesis activities of the anti-GRP DNA vaccine offered a novel immunotherapeutic approach in the treatment of GRP-dependent tumors and their complications.
\end{abstract}

Endocrine-Related Cancer (2009) 16 1171-1184

\section{Introduction}

Over the last two decades, several lines of experimental evidence have suggested that the gastrin-releasing peptide (GRP) may act as a growth factor in many types of cancer. The GRP mediates its effects by binding to the GRP receptor (GRPR) which is expressed aberrantly in various cancer cells (Cornelio et al. 2007). In addition, recent data show that GRP is not only an autocrine mitogen, but also has paracrine and endocrine effects, and functions as a morphogen and a pro-angiogenic agent (Xiangping et al. 2003). This elevated expressions and receptor-binding activity of GRP in various types of cancer suggest that GRP might be a viable target for immunotherapy in neoplastic diseases.

DNA vaccines have become an attractive approach for generating antigen-specific immunotherapy. The naked plasmid DNA is safe, has low immunogenicity, and can be repeatedly administered. DNA vaccines can be easily prepared on a large scale with high purity and are highly stable relative to proteins and other biological polymers (Donnelly et al. 1997). However, 
a key issue in developing subunit DNA vaccines is their relatively weak immunogenicity. Consequently, alternative strategies have been considered and tested experimentally to avoid this significant problem. This lead to the identification of effective DNA vaccine delivery systems and the optimization of the expression of the encoded vaccine antigens (Greenland \& Letvin 2007), DNA-elicited immune responses can be enhanced and modulated by the use of plasmid-based molecular adjuvants, for example, targeting antigens to the endoplasmic reticulum for rapid intracellular degradation (Hung et al. 2001), directing antigens to antigen presenting cells (APCs) by fusion to ligands for APC receptors (Cusi et al. 2004), fusing antigens to chemokines (Biragyn et al. 1999) or to pathogen sequences (King et al. 1998), coinjecting cytokines (Calarota \& Weiner 2004), costimulatory molecules (Calarota \& Weiner 2004) and co-administration with CpG oligonucleotides (Klinman et al. 1997). However, DNA vaccines with these adjuvants have not been proven to induce impressive protection against infection of several pathogens or neoplastic diseases, particularly in non-human primates. Thus, additional research for novel and potent adjuvants for DNA vaccine is needed.

In the current study, anti-GRP DNA vaccines have been designed to induce specific deprivation of GRP by a strong humoral immune response. To break the already established tolerance of this self-peptide in vivo, six copies of the B cell epitope $\mathrm{GRP}_{18-27}$ (Papac et al. 1994) in a linear alignment (GRP6) have been inserted into an eukaryotic expression vector (pCR3.1) as an immunogen. Furthermore, tandem repeated $\mathrm{GRP}_{18-27}$ was fused to different immunoadjuvants to optimize its immunogenicity, including mycobacterial heat shock protein $65 \mathrm{kDa}$ (HSP65; Perraut et al. 1993), tetanus toxoid fragment 830-844 (Kumar et al. 1992), pan HLA-DR-binding epitope (Alexander et al. 2000), and mycobacterial HSP70 fragment 407-426 (Wang et al. 2005). The efficacy of the anti-GRP DNA vaccines were tested on the RM-1 murine prostate carcinoma model, the growth of which can be regulated by GRP and anti-GRP antibodies (Abs) in vitro. Finally, the inhibition of tumor-induced angiogenesis induced by active immune responses was evaluated in an intradermal tumor model in vivo.

\section{Materials and methods}

\section{Tumor cell line and mice}

The murine RM-1 prostate carcinoma cell line was obtained from the Institute of Biochemistry and Cell Biology of the Chinese Academy of Sciences,
Beijing, China. Tumor cells were cultured in growth medium containing DMEM supplemented with $10 \%$ fetal bovine serum, $2 \mathrm{mmol} / \mathrm{l}$ glutamine, $100 \mathrm{U} / \mathrm{ml}$ penicillin, $100 \mu \mathrm{g} / \mathrm{ml}$ streptomycin at $37^{\circ} \mathrm{C}$ under humidified atmosphere of $95 \%$ air $/ 5 \% \quad \mathrm{CO}_{2}$. For all experiments, male C57BL6 mice, 5 weeks old, obtained from the Chinese Academy of Medical Sciences, Beijing, China were used. Animals were housed in pathogen-free conditions during the studies, and their care was in accord with institutional guidelines. All procedures in animal experiments were approved by the Institutional Animal Ethical Committee of China Pharmaceutical University.

\section{Construction of DNA vaccines}

Construction of plasmid pCR3.1-VS-HSP65-TP-GRP6

The plasmid pCR3.1 containing the VEGF183 signal peptide (VS, under the control of promoter CMV) and eight $5^{\prime}$-GACGTT-3' CpG motifs (on its backbone) was used as the eukaryotic expression vector. The gene encoding HSP65-GRP6 was obtained by PCR from plasmid pET28a-HG6 (Guojun et al. 2008), using A1 (5'-CACCCATGGCCAAGACAATT- $\left.3^{\prime}\right)$ and A2 (5'-ATCTAGACGCTAAGCTTGCG-3 $\left.{ }^{\prime}\right)$ as forward and reverse primers, respectively. The gene encoding tetanus toxoid ${ }_{830-844}$-PADRE (TP) was amplified by PCR with B1 (5'-GCGTCTAGAGGTGGCGGTGGCTCCGGTGGCGGTGGCTCCGGATCTCAGTACATCAAGG-3'), B2 (5'-GATCTCAGTACATCAAG GCTAACTCTAAGTTCATCGGCATTACCGAGCTGTCCCCTG-3'), B3 (5'-CTTCAGGGTCCAAGCGGCCACGAACTTGGCAGAGCCAGGGGACAGCTCGGTAATGCC-3'), B4 (5'-ACTTGCTAGCGGA TCCAGGGCCAGGGCCAGCAGCGGCCTTCAGGGTCCAAGCGGCC- $3^{\prime}$ ) as both primers and templates. Both the plasmid vector and gene encoding HSP65GRP6 were digested by NcoI and HimdIII, and then ligated. The newly formed plasmid was named pCR3.1-VS-HSP65-GRP6 and digested again by NheI and treated with calf intestinal alkaline phosphatase (CIAP), then ligated with TP gene digested by NheI and XabI to construct the plasmid pCR3.1VS-HSP65-TP-GRP6.

Construction of plasmid containing tandem repeats (from 1 to 3) of $\mathrm{HSP}_{407-426}$ gene (M)

These three plasmids were constructed according to the method described by Yankai et al. (2006) with slight modifications. The encoding sequence of $M$ gene was synthesized by PCR with two 
oligonucleotides used as both primers and templates: C1 (5'-ATAGCTAGCGCCAGATCTCCTGGCAGCCAGCCTTCCGTGCAGATCCAGGTCTACCAGGGCGAGCGC-3'), C2 (5'-GCGAAGCTTAGCGTCTA GATGAGG ATCCCTTGTTGTGAGCGGCAATCTCGCGCTCGCCCTGGTAGAC- $3^{\prime}$ ). M gene was inserted into the plasmid pCR3.1-VS-HSP65TP-GRP6 behind GRP6 gene.

\section{Construction of plasmid pCR3.1-VS-HSP65-TP-M2}

The gene encoding two copies of M (M2) was amplified by PCR from plasmid pCR3.1-VS-HSP65-TP-GRP6-M2 using D1 (5'-TTAGCTAGCGCCAGATCTCCTGGCAGC- $\left.3^{\prime}\right)$ and D2 (5'-TTAAAGCTTAGCGTCTAGATGAGGATC- $3^{\prime}$ ) as forward and reverse primers respectively. pCR3.1-VS-HSP65-TP-M2 was constructed by digestion of pCR3.1-VS-HSP65TP-GRP6-M2 with NheI and HimdIII, and then ligated with M2 digested by the same restriction enzymes. This plasmid served as a vaccine control.

All constructed DNA vaccines and controls listed in Fig. 1 were verified by DNA sequencing.

\section{DNA immunization procedure}

Plasmid DNA used for immunization was purified using Qiagen Plasmid Mega Kit (Qiagen) and suspended in sterile saline at a concentration of

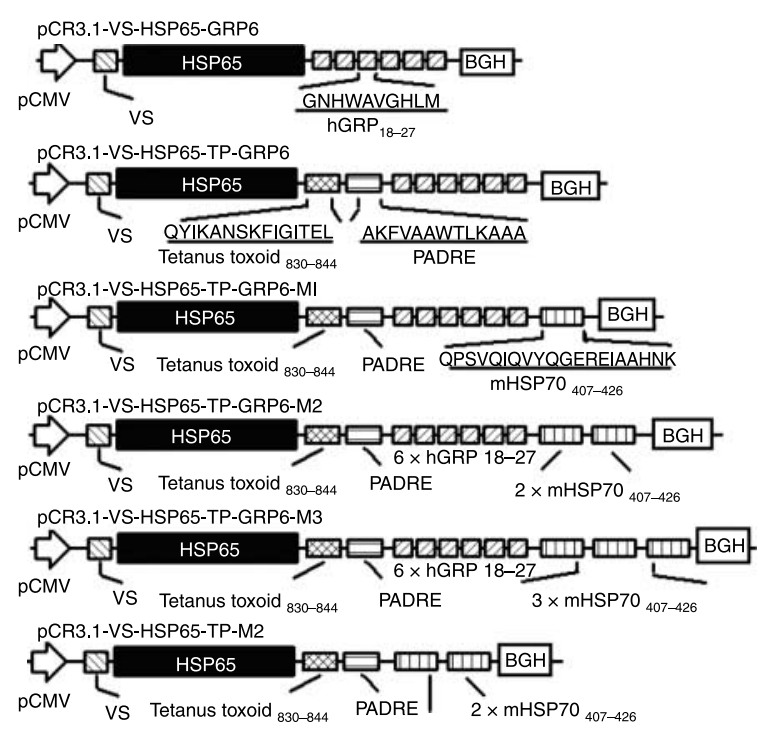

Figure 1 Schematic diagram of the constructed anti-GRP DNA vaccines. Take pCR3.1-VS-HSP65-TP-GRP6-M2 as an example. The VS gene (VS, $\square$ ) was placed under the control of promoter CMV $(\hookrightarrow)$, followed sequentially by the genes encoding for HSP65 $(\square)$, tetanus toxoid ${ }_{830-844}(T, \infty$ ), PADRE $(P, \square)$, six tandem repeats of hGRP ${ }_{18-27}(\mathrm{GRP} 6, \square)$, and two copies of mycobacterial HSP70 $407-426$ (M2, 四).
$0.5 \mu \mathrm{g} / \mu \mathrm{l}$. A total of eight C57BL6 male syngeneic mice $(n=8)$ were used for each experimental group (one group for each of the six plasmid DNA and saline control). Mice were anesthetized via i.m. injections in the anterior thigh with $100 \mu \mathrm{l}$ of $0.25 \%$ bupivacaine hydrochloride solution. Seventy-two hours later, mice received i.m. injections of $100 \mu \mathrm{l}$ each of the plasmid DNA vaccines $(0.5 \mu \mathrm{g} / \mu \mathrm{l})$ or saline. Booster injections were given every other week (weeks 3 and 5) using the same protocol. Sera were taken at various time points for later analyses of antibody titers.

\section{Detection of antibodies by ELISA}

The amount of anti-GRP Abs and anti-HSP65 Abs in the immune sera was determined using ELISA as described by Yankai et al. (2006). Briefly, 96-well flatbottomed ELISA plates were coated with $2 \mu \mathrm{g} /$ well of $\mathrm{GRP}_{1-27}$ peptide (Sigma) or $2 \mu \mathrm{g} /$ well of recombinant HSP65 (Xu et al. 2008). Plates were washed and blocked, and individual sera from immunized and control mice were added to the wells at the indicated dilutions. This was followed by incubation in HRPconjugated goat anti-mouse IgG (Sigma). The reaction was completed using 3,3',5,5'-tetramethylbenzidine and absorbances were measured at a wavelength of $450 \mathrm{~nm}$. Endpoint titers were defined as the dilution where the optical density (OD450) exceeded the cut-off value. Cut-off was calculated as the mean $\mathrm{OD} 450+$ three times the s.D., from sera from control plasmid vaccinated mice at a dilution of 1:200. Each sample in the assay was performed in duplicate.

To determine the specific isotypes, individual sera from mice were diluted 1:200 and tested in duplicate. For detection of mouse IgG1 and IgG2a isotypes, we used anti-mouse Ig subclass-specific, HRP-conjugated secondary Abs (Sigma).

\section{Specificity of anti-GRP and anti-HSP65 antibodies}

The method for Dot Blots was similar to that described by Perschinka et al. (2003) and Guojun et al. (2008). Briefly, a $2 \mu \mathrm{g} /$ dot $\mathrm{GRP}_{1-27}$ was air-dried on a nitrocellulose membrane (Millipore, Bedford, MA, USA). For detection of the specificity of anti-HSP65 Abs, purified HSP65 recombinant proteins were separated on a $12 \%$ SDS-PAGE gel, then transferred onto nitrocellulose membranes. The membranes were blocked, washed and probed with 1:200 dilution of pooled immune sera collected from mice immunized with various DNA vaccines. Blots were then washed and incubated with HRP-conjugated goat anti-mouse 
IgG (Sigma). The reaction was developed by using $0.05 \%(\mathrm{w} / \mathrm{v}) 3,3^{\prime}$-diaminobenzidine tetrahydrochloride and $0.012 \%(\mathrm{v} / \mathrm{v}) \mathrm{H}_{2} \mathrm{O}_{2}$ for $15 \mathrm{~min}$ at $37^{\circ} \mathrm{C}$.

\section{Determination of relative avidity of anti-GRP antibodies}

The method for avidity assays was similar to that described by Pullen et al. (1986). Briefly, ELISA plates were coated with $2 \mu \mathrm{g} /$ well of $\mathrm{GRP}_{1-27}$ peptide. Plates were blocked and then incubated with $100 \mu \mathrm{l} /$ well 1:200 diluted sera from pCR3.1-VS-HSP65-TP-GRP6 immunized mice and $100 \mu \mathrm{l} /$ well 1:12 800 diluted sera from pCR3.1-VS-HSP65-TP-GRP6-M2 immunized mice (sera were collected 2 weeks after the last booster injection). After incubation, wells were washed and incubated with $100 \mu \mathrm{l}$ of serial dilutions of $0-3 \mathrm{M}$ sodium thiocyanate (NaSCN, Sigma), a chaotropic compound that interferes with the antigen-antibody reaction, in PBS. The wells were incubated for $15 \mathrm{~min}$ at room temperature before washing. The remainder of the assay was done similar to the ELISA analysis for anti-GRP Abs.

\section{T cell proliferation assay}

Fourteen days after the last nasal immunization, mice were killed to obtain splenocytes. Proliferation of purified $\mathrm{T}$ cells to various antigens was detected following the procedure previously described (Jin et al. 2008). Briefly, $100 \mu \mathrm{T}$ cell cultures $\left(5 \times 10^{6}\right.$ cells $\left./ \mathrm{ml}\right)$ were incubated for $72 \mathrm{~h}$ in the presence of $10 \mu \mathrm{g} / \mathrm{ml}$ HSP65, tetanus toxoid $830-844$, PADRE, and $\mathrm{mHSP}_{407-426}$ respectively (peptides were synthesized by using an automated multiple peptide synthesizer following the company's protocols for $\mathrm{N}$-a-fluorenylmethoxycarbonyl synthesis). ConA $(1.25 \mu \mathrm{g} / \mathrm{ml})$ was used as a positive control. Each sample was plated in triplicate. T cell responses were detected by the methyl thiazolyl tetrazolium (MTT) method.

\section{Affinity chromatography isolation of anti-GRP antibodies}

Recombinant GFP-GRP ${ }_{18-27}$ proteins (Guojun et al. 2008) was coupled to NHS-activated sepharose 4FF (Pharmacia) according to the manufacturer's recommendation. Pooled anti-GRP sera from mice immunized with pCR3.1-VS-HSP65-TP-GRP6-M2 were inactivated and precipitated twice with $50 \%$ saturated and 33\%-saturated $\left(\mathrm{NH}_{4}\right)_{2} \mathrm{SO}_{4}$ respectively. Then the precipitated IgGs, dialyzed against PBS overnight, were added to the column. After $30 \mathrm{~min}$ incubation, $20 \mathrm{mmol} / \mathrm{l}$ Gly-HCl buffer ( $\mathrm{pH} 2.5$ ) was added to wash antibodies. The eluant was immediately neutralized with $1 \mathrm{~mol} / \mathrm{l}$ Tris- $\mathrm{HCl}(\mathrm{pH} 8.0)$, then dialyzed against PBS. The concentration of anti-GRP Abs was determined with the Coomassie Plus protein assay reagent kit (Pierce, Rockford, IL).

\section{Cell proliferation assay}

The effects of the $\mathrm{GRP}_{1-27}$ full peptide, immune sera or purified anti-GRP Abs on the proliferation of RM-1 cells were measured using the MTT assay (Guojun et al. 2008). Briefly, RM-1 cells plated on 96-well plates at $1 \times 10^{4}$ cells per well were incubated with serial dilutions of the $\mathrm{GRP}_{1-27}$ peptide, pooled immune sera from each immunized group or purified anti-GRP Abs for $48 \mathrm{~h}$ followed by $20 \mu \mathrm{l}$ of MTT for $4 \mathrm{~h}$. At the end of the incubation, absorbances were read at $570 \mathrm{~nm}$. All assays were performed in triplicate.

\section{RM-1 prostate carcinoma model}

In order to analyze the antitumor effect of anti-GRP DNA vaccines, a vaccination protocol was designed as shown in Fig. 2A. Mice (eight per group) were immunized three times every 2 weeks followed by s.c. injections of $1 \times 10^{6} \mathrm{RM}-1$ cells into the left flank. After 14 days, the animals were killed, and solid tumors were excised and weighed.

\section{Quantification of angiogenesis in vivo}

As shown in Fig. 2A, a vaccination protocol was designed for each experimental group (four mice per group). To visualize the induction of angiogenesis by a tumor in vivo, an intradermal tumor model was used. In this model, neovasculature, observed predominantly at the tumor periphery, can be quantified by vessel counting (Kreisle \& Ershler 1988). At day 0, mice were anesthetized (inhalant 4\% Halothane-vet), and $2.5 \times 10^{6} \mathrm{RM}-1$ viable cells in $50 \mu \mathrm{l}$ of PBS were implanted intradermally at two sites in the abdominal region. Two additional injections of PBS $(50 \mu \mathrm{l})$ were performed on each mouse as a control. All implant sites were marked with indelible ink to aid identification at the end of the experiment. When the intradermal tumor grows up to $5 \mathrm{~mm}$ in diameter, a section of the abdominal wall skin encompassing all implant sites was removed and spread onto filter paper. Sections were examined by light microscopy ( $\times 10$ magnification), and the total number of blood vessels (major vessels and branching points) was determined within a $1 \mathrm{~cm}^{2}$ area around each implant site. Vessel counts from implants 

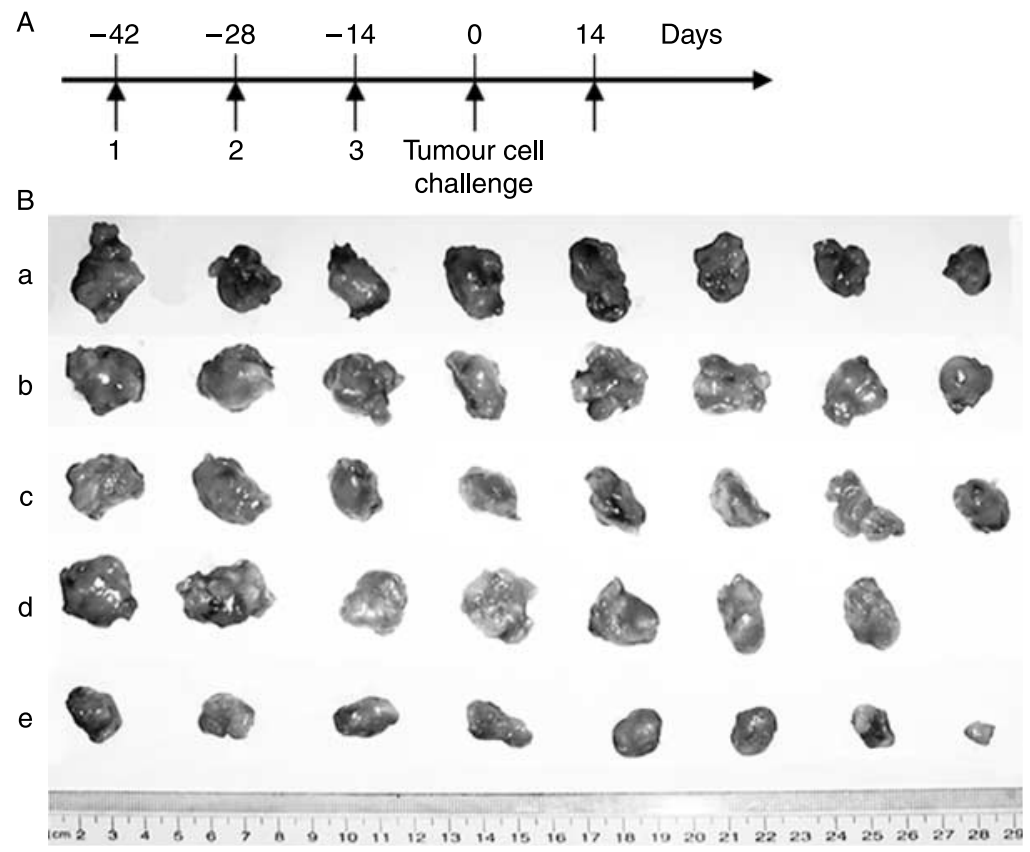

Figure 2 Effects on RM-1 tumor model of anti-GRP DNA vaccine. (A) The immunization scheme indicates the days of vaccination by arrows. Mice were immunized with anti-GRP DNA vaccines day $-42,-28$, and -14 . At day $0,1 \times 10^{6}$ RM- 1 prostate tumor cells were injected subcutaneously for tumor cell challenge. Fourteen days later, all mice were killed and tumors were excised and weighted. (B) The RM-1 prostate tumors from immunized mice. The picture shows the tumors extracted from mice immunized with saline (a, control $n=8$ ), pCR3.1-VS-HSP65-TP-M2 (b, control $n=8$ ), pCR3.1-VS-HSP65-TP-GRP6 (c, $n=8$ ), pCR3.1-VS-HSP65TP-GRP6-M1 (d, $n=7$ ), pCR3.1-VS-HSP65-TP-GRP6-M2 (e, control $n=8$ ).

of PBS were consistent irrespective of treatment; the mean value was therefore subtracted from control and vaccines immunized vessel counts to give a more accurate indication of tumor-induced blood vessel formation and to ascertain the effect of treatment.

\section{Histological evaluation of the intradermal tumors}

Intradermal tumors (five tumors per group) were fixed in $4 \%$ paraformaldehyde, paraffin embedded, cut into $5 \mu \mathrm{m}$ sections. Periodic acid-Schiff (PAS) staining with hematoxylin counterstaining was then performed to the tumor sections.

\section{Statistical analysis}

Data were collected and subjected to statistical analyses using Student's $t$-test. Differences were considered significant at $P<0.05$.

\section{Results}

\section{Induction of anti-GRP and anti-HSP65 antibodies in immunized mice}

To investigate whether DNA vaccines (Fig. 1) containing 6 tandem repeats of $\mathrm{GRP}_{18-27}$ could evoke a strong humoral immune response, we compared the levels of GRP-specific IgG in the sera collected from immunized mice by ELISA (Fig. 3). Sera samples were collected at 3,5, and 7 weeks after initial immunization. All GRP-based DNA vaccines, as compared with the control vaccine (pCR3.1-VS-HSP65-TP-M2) or saline control, greatly increased titers of specific antiGRP Abs 5 weeks post-inoculation and the antibody levels remained high up to 7 weeks post-inoculation. The average anti-GRP Abs titers in mice immunized with the plasmid containing two copies of the $\mathrm{M}$ (endpoint dilution: 51200 ) were the highest 7 weeks post-immunization as compared with other GRPbased vaccines (endpoint dilution: from 800 to 3200). These data clearly demonstrated that two copies of $\mathrm{HSP}_{407-426}$ gene were highly potent in augmenting humoral response and immunogenicity of the antiGRP vaccine.

Interestingly, the antibody response to GRP (endpoint dilution: 51200 ) was superior to the carrier protein HSP65 (endpoint dilution: 6400) when plasmids containing two copies of the M (Fig. 4A) were present. It appears that the reduced humoral responses to the carrier protein may allow a greater portion of the immune response to be directed to the therapeutically relevant portion of the vaccine. 

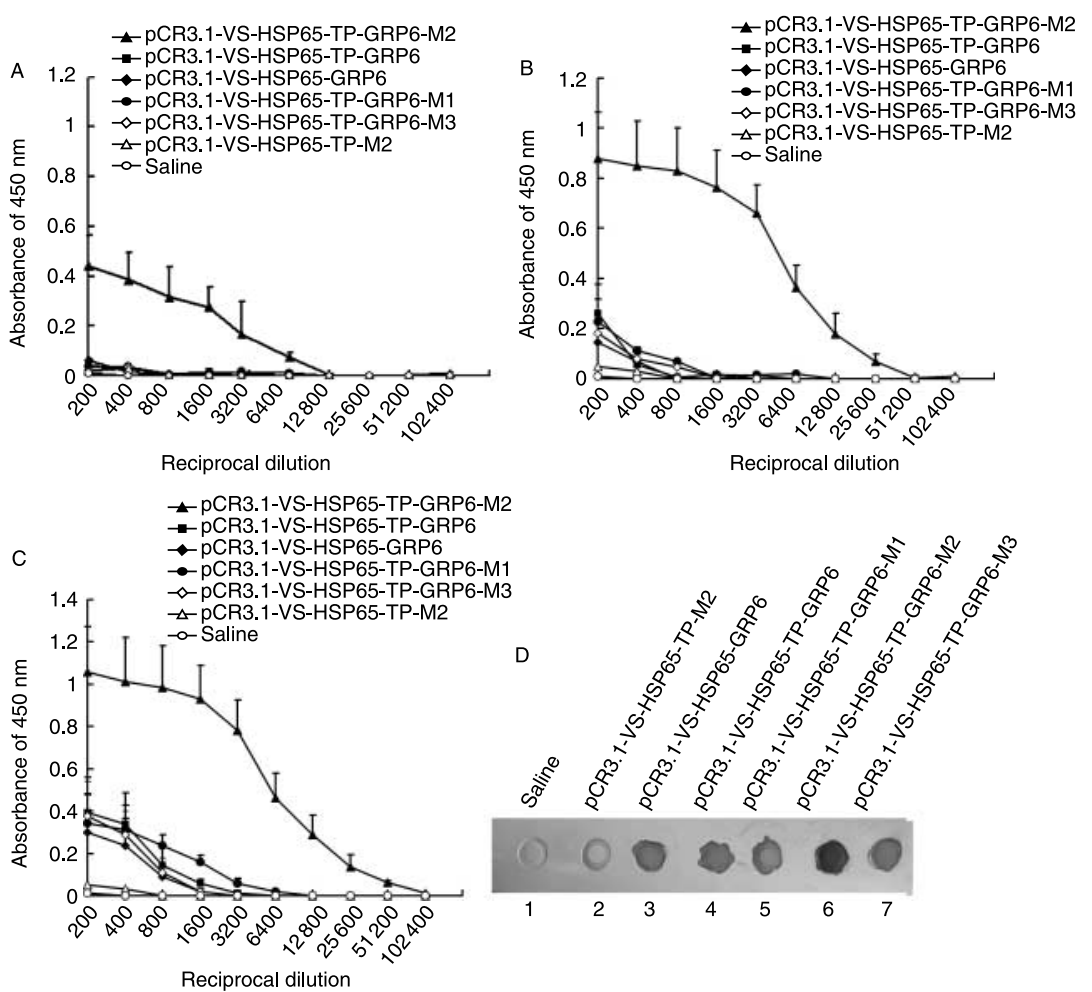

Figure 3 Detection of anti-GRP antibodies. Each group of mice $(n=8)$ was immunized i.m. with $50 \mu \mathrm{g}$ of plasmids at 1,3 , and 5 weeks. Individual serum samples were collected at 3 weeks (A), 5 weeks (B), and 7 weeks (C). The sera were tested for the presence of anti-GRP Abs in ELISA. Data represent mean \pm s.E.M. Mice immunized with pCR3.1-VS-HSP65-TP-GRP6-M2 produced the highest titers of anti-GRP Abs than any other groups. (D) The specificity of anti-GRP Abs elicited in immunized mice was established by immunoblots using $\mathrm{GRP}_{1-27}$ as antigen. Sera from mice immunized with all GRP-based DNA vaccines reacted with $\mathrm{GRP}_{1-27}$ (dots 3-7), while sera from vaccine control group or saline group did not react with $\mathrm{GRP}_{1-27}($ dots $1-2)$.

\section{Anti-GRP and anti-HSP65 antibodies analysis by western blot}

The specificity of antibodies elicited in immunized mice was established by immunoblots using $\mathrm{GRP}_{1-27}$ and recombinant HSP65 protein as antigens. Antibodies from mice immunized with all GRP-based DNA vaccines reacted with $\mathrm{GRP}_{1-27}$ (dots 3-7, Fig. 3D), while sera from vaccine control group or saline group did not react with $\mathrm{GRP}_{1-27}$ (dots 1-2, Fig. 3D). Specific anti-HSP65 Abs were also detected by immunoblots using purified HSP65 as antigen (Fig. 4B). These findings suggested that the antibodies in the immune sera specifically recognized the GRP and HSP65 antigens.

\section{Relative avidity of anti-GRP antibodies}

To further investigate the relationship between the antibody titers and the biological effects of the GRP vaccines, avidity assays were performed on diluted antisera with equalized anti-GRP Abs titers from mice $(n=8$, week 7$)$ immunized with
pCR3.1-VS-HSP65-TP-GRP6 or pCR3.1-VS-HSP65TP-GRP6-M2. The relative avidities of antibodies were observed based on the concentration of $\mathrm{NaSCN}$ required to depress the value of $\mathrm{OD}_{450}$ to half its initial value. The mean relative avidity of antibodies in the group vaccinated with pCR3.1-VS-HSP65TP-GRP6-M2 was significantly higher than that from the group immunized with pCR3.1-VS-HSP65TP-GRP6 (1.09 \pm 0.14 vs $0.64 \pm 0.11 \mathrm{M}, P<0.01$; Fig. 5C). All these data clearly demonstrated that two copies of $\mathrm{HSP} 0_{407-426}$ gene were highly potent in augmenting the humoral response and immunogenicity of the anti-GRP vaccine.

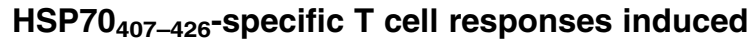 Th1-polarized immune responses}

To investigate which $\mathrm{T}$ cell epitopes are responsible for the generation of $\mathrm{Th}$ cells, $\mathrm{T}$ cell proliferation to various $\mathrm{T}$ cell epitopes was tested (Fig. 5A). Although $\mathrm{T}$ cell proliferation was noticeably induced by the stimulation of ConA in saline, pCR3.1-VS-HSP65TP-GRP6 and pCR3.1-VS-HSP65-TP-GRP6-M2 


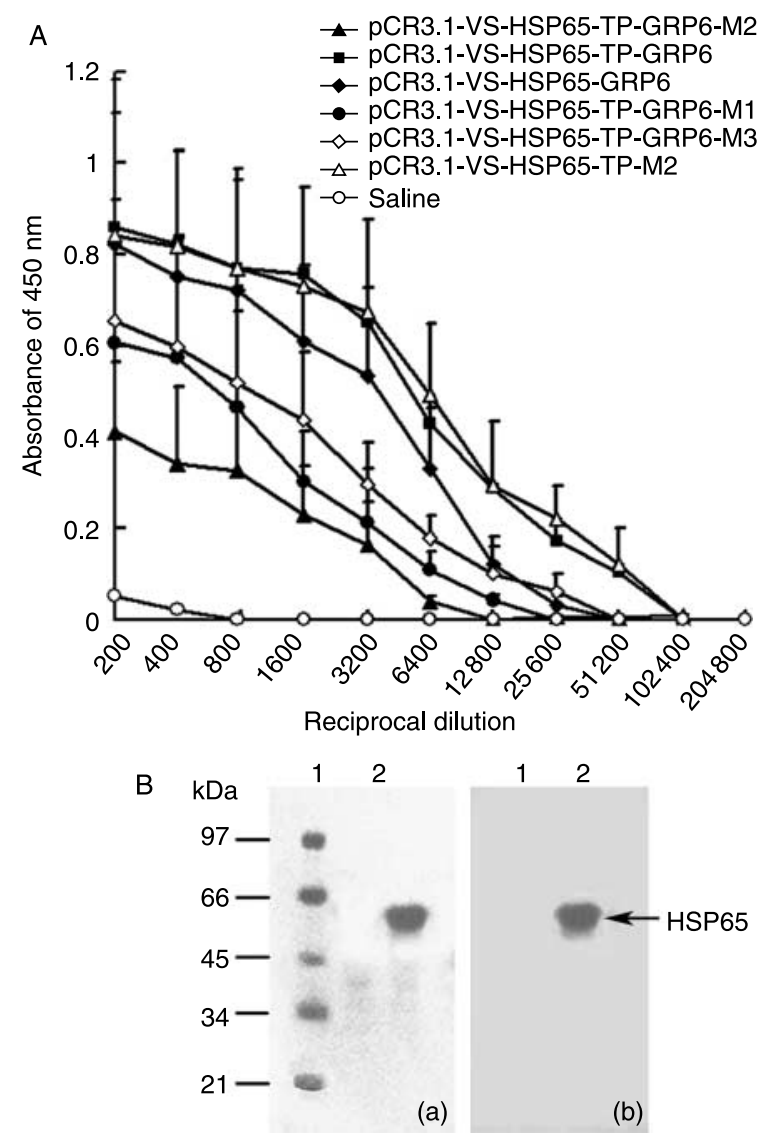

Figure 4 Detection of anti-HSP65 antibodies. Each group of mice $(n=8)$ was immunized i.m. with $50 \mu \mathrm{g}$ of plasmids at 1,3 and 5 weeks. Individual serum samples were collected at 7 weeks (A). The sera were tested for the presence of anti-HSP65 Abs in ELISA. Data represent mean \pm S.E.M. Mice immunized with pCR3.1-VS-HSP65-TP-GRP6-M2 produced the lowest titers of anti-HSP65 Abs than any of the other anti-GRP DNA vaccine immunized groups. (B) The specificity of anti-HSP65 Abs elicited in pCR3.1-VS-HSP65-TP-GRP6-M2 immunized mice was established by immunoblots using HSP65 as antigen. (a) Proteins on nitrocellulose membrane stained by ponceau after being transferred from 12\% SDS-PAGE gel. (b) Result of western blotting (lane1, protein molecular weight marker; lane2, HSP65). Sera from mice immunized with other plasmids showed the similar results (data not shown).

treated groups, HSP65, tetanus toxoid ${ }_{830-844}$, and PADRE did not induce $\mathrm{T}$ cell proliferation. Importantly, $\mathrm{T}$ cells isolated from mice immunized with pCR3.1-VS-HSP65-TP-GRP6-M2 induced strong T cell proliferation after stimulation with $\mathrm{HSP} 0_{407-426}$, indicating $\mathrm{HSP}_{407-426}$ was responsible for the generation of Th cells and GRP-specific Abs.

When functioning in vivo as an adjuvant, the C-terminal portion of mHSP70 (aa 359-610) is well known for the induction of Th1 polarized immune responses (Wang et al. 2002). In addition, $\mathrm{mHSP}_{407-426}$ was identified as a major epitope stimulating Th1-polarizing cytokines (Wang et al. 2005). In this study, we measured the production of IgG1 (Th2 response) and IgG2a (Th1 response) anti-GRP Abs in our experiments to indirectly demonstrate the relative contributions of Th2 versus Th1 responses (Agadjanyan et al. 2005). As expected, the anti-GRP Abs induced by pCR3.1-VS-HSP65TP-GRP6-M2 were almost exclusively of IgG2a
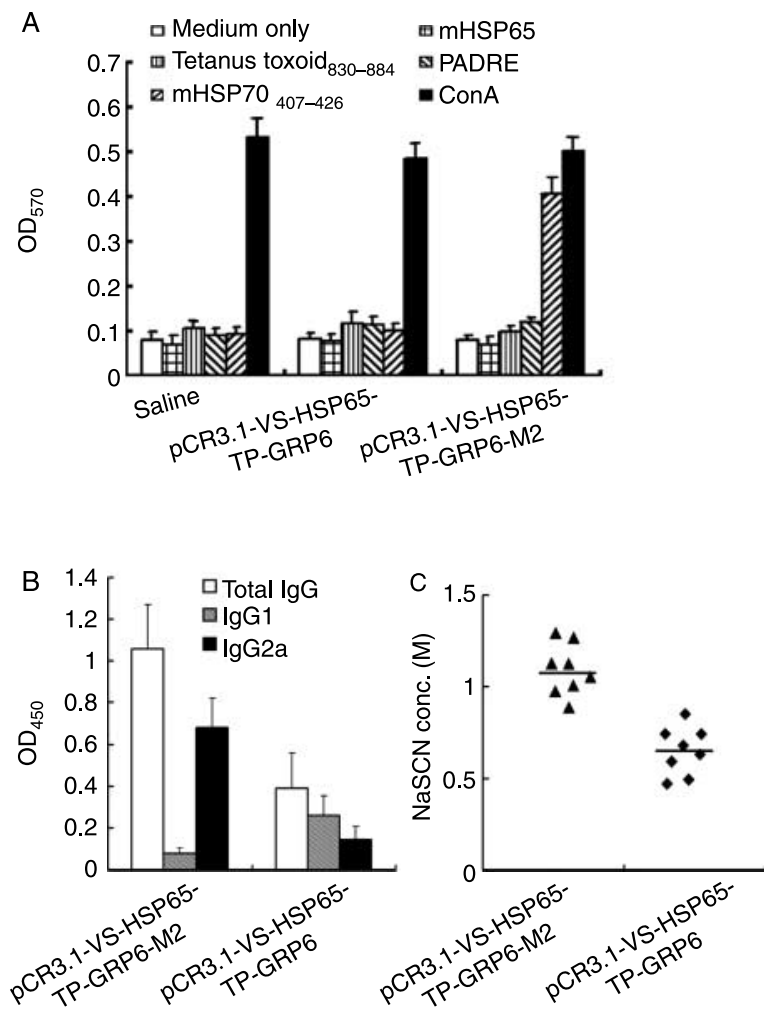

Figure $5 \mathrm{HSP}_{407-426}$-specific $\mathrm{T}$ cell responses induced a Th1-polarized immune response. Mice $(n=4)$ were immunized with pCR3.1-VS-HSP65-TP-GRP6-M2, pCR3.1-VS-HSP65TP-GRP6 and PBS. Two weeks after the last immunization, the spleens were removed and the $\mathrm{T}$ cell proliferative responses were assayed in vitro after $72 \mathrm{~h}$ of stimulation with $10 \mu \mathrm{g} / \mathrm{ml}$ mHSP65, tetanus toxoid ${ }_{830-844}$, PADRE, and $\mathrm{mHSP}_{407-426}$ or $1.25 \mu \mathrm{g} / \mathrm{ml}$ T cell mitogen ConA. Data were expressed as mean \pm S.E.M. ${ }^{\star \star} P<0.01$ compared with medium treated $T$ cells in the same group. (B) IgG subclass determination. Sera from mice ( $n=8$, week 7$)$ immunized with pCR3.1-VS-HSP65TP-GRP6-M2, pCR3.1-VS-HSP65-TP-GRP6 were tested on $\mathrm{GRP}_{1-27}$-coated wells and detected with peroxidase conjugated monoclonal anti-mouse IgG1 and IgG2a Abs. Data were expressed as mean \pm S.E.M. (C) Diluted antisera with equalized anti-GRP Abs titers from mice $(n=8$, week 7$)$ immunized with pCR3.1-VS-HSP65-TP-GRP6 or pCR3.1-VS-HSP65-

TP-GRP6-M2 were examined for their binding avidity to GRP in a modified ELISA. The results were expressed as the concentration of sodium thiocyanate (NaSCN) that was required to disrupt antibodies binding to GRP. Anti-GRP Abs from sera of mice immunized with $\mathrm{HSP}_{407-426}$-containing plasmids had significantly higher relative avidity as compared with those without. ${ }^{\star \star} P<0.01$. 
subclass, which is indicative of Th1 response (Fig. 5B). Furthermore, we determined the IgG2a/IgG1 ratios for anti-GRP Abs. The IgG2a/IgG1 ratio for pCR3.1-VS-HSP65-TP-GRP6-M2 immunized mice (8.5) was 15 times greater than that for pCR3.1-VS-HSP65-TP-GRP6 (0.56). These data suggest that the introduction of two copies of HSP70 $_{407-426}$ as a T-helper epitope induced a highly Th1-polarized immune responses in mice.

\section{GRP $_{1-27}$ peptide stimulated the proliferation of $\mathrm{RM}-1$ cells in vitro}

To determine the effect of GRP on murine prostate carcinoma, RM-1 cells plated in 96-well plates were incubated with full GRP peptide $\left(\mathrm{GRP}_{1-27}\right)$ in concentrations of $10^{-5}-10^{-11} \mathrm{~mol} / \mathrm{l}$. The number of RM-1 cells increased in a dose-dependent fashion in direct relation to the concentration of the full-length peptide $\mathrm{GRP}_{1-27}$ (Table 1). A significant mitogenic effect, as compared with control, was observed starting initially at $10^{-9} \mathrm{~mol} / \mathrm{l}(\mathrm{SR} \%=17.6 \% ; P<0.05)$ and increased at higher doses with a stimulation rate of $57.9 \%$ at $10^{-5} \mathrm{~mol} / \mathrm{l}$.

\section{Anti-GRP Abs inhibited the growth of RM-1 cells in vitro}

To determine the inhibitory effect of anti-GRP Abs on RM-1 cells in vitro, cultured RM-1 cells were incubated with antibodies against GRP (affinity purified) 50 to $0.87 \mu \mathrm{g} / \mathrm{ml}$. The growth of RM-1 cells was suppressed by anti-GRP Abs in a dose-dependent manner (Table 2). Significant inhibitory effects as compared with control were observed initially at $1.56 \mu \mathrm{g} / \mathrm{ml}$ (inhibition rate \% $($ IR\%) $=19.7 \%$; $P<0.05)$ and further increased at higher doses with an IR of $43.3 \%$ at $50 \mu \mathrm{g} / \mathrm{ml}$. Moreover, similar results were also obtained in vitro showing inhibition of RM-1 cell proliferation in a dose-dependent manner by the antisera from pCR3.1-VS-HSP65-TP-GRP6-M2 immunized mice (Table 3). With the dilutions at 1:10 and 1:2, the antisera showed IRs similar to that obtained from purified anti-GRP Abs at 1.56 and $12.5 \mu \mathrm{g} / \mathrm{ml}$, respectively. Antisera from other groups of mice did not significantly inhibit the proliferation of RM-1 cells, possibly due to the low titers of anti-GRP Abs generated in these groups of mice.

\section{Effect on RM-1 prostate carcinoma model}

To determine whether vaccination with pCR3.1VS-HSP65-TP-GRP6-M2 could protect mice against RM-1 prostate carcinoma and whether the introduction of two copies of the HSP70 $407-426$ gene in this DNA vaccine would also enhance the anti-tumor effects along with remarkably increased levels of specific antibodies, we applied the RM-1 prostate carcinoma model in this study. The plasmids pCR3.1-VS-HSP65GRP6 and pCR3.1-VS-HSP65-TP-GRP6-M3 were excluded from this study because the former elicited an anti-GRP Abs level comparative to that elicited by pCR3.1-VS-HSP65-TP-GRP6, and the latter elicited an anti-GRP Abs level comparative to that elicited by pCR3.1-VS-HSP65-TP-GRP6-M1. The size and weights of tumors removed from all immunized mice on day 14 after tumor cell challenge of the five experimental groups are shown in Fig. 2B and Table 4 respectively. The tumor weights distinctly indicated that tumor regression was more pronounced in the animals immunized with pCR3.1-VS-HSP65-TPGRP6-M2 compared with that in the mice immunized with saline $(P=0.004)$, pCR3.1-VS-HSP65-TP-M2 $(P=0.0003)$, pCR3.1-VS-HSP65-TP-GRP6 $(P=0.003)$, or pCR3.1-VS-HSP65-TP-GRP6-M1 $(P=0.002)$. However, tumor weight in mice immunized with pCR3.1-VS-HSP65-TP-M2 $(P=0.985)$, pCR3.1VS-HSP65-TP-GRP6 $(P=0.238)$, or pCR3.1-VSHSP65-TP-GRP6-M1 $(P=0.579)$ was not significantly lower than that of the saline control. As the results show, pCR3.1-VS-HSP65-TP-GRP6-M2 could strongly elicit anti-tumor immunity against the growth of RM-1 mainly benefiting from the introduction of two repeats of $M$ fragments after the GRP6 fragment.

Table $1 \mathrm{GRP}_{1-27}$ peptides stimulate the proliferation of cultured $\mathrm{RM}-1$ cells

\begin{tabular}{|c|c|c|c|c|c|}
\hline Dose $(\mathrm{mol} / \mathrm{l})$ & $\boldsymbol{A}_{570}(x \pm s, n=3)$ & SR\% & Dose (mol/l) & $\boldsymbol{A}_{570}(x \pm s, n=3)$ & SR\% \\
\hline Control & $0.693 \pm 0.097$ & & $10^{-8}$ & $0.886 \pm 0.009^{\dagger}$ & 27.8 \\
\hline $10^{-11}$ & $0.767 \pm 0.159$ & 10.7 & $10^{-7}$ & $0.972 \pm 0.065^{\dagger}$ & 40.2 \\
\hline $10^{-10}$ & $0.788 \pm 0.043$ & 13.7 & $10^{-6}$ & $1.003 \pm 0.084^{\dagger}$ & 44.7 \\
\hline $10^{-9}$ & $0.816 \pm 0.134^{*}$ & 17.6 & $10^{-5}$ & $1.095 \pm 0.117^{\dagger}$ & 57.9 \\
\hline
\end{tabular}

${ }^{\star} P<0.05$ versus control; ${ }^{\dagger} P<0.01$ versus control; SR\%, stimulation rate (\%). 
Table 2 Suppression on the proliferation of RM-1 cells with different gastrin-releasing peptide (GRP) Abs level

\begin{tabular}{lcccc}
\hline Dose $(\mu \mathrm{g} / \mathrm{ml})$ & $\boldsymbol{A}_{\mathbf{5 7 0}}(x \pm s, n=3)$ & IR\% & Dose $(\mu \mathrm{g} / \mathrm{ml})$ & $\boldsymbol{A}_{\mathbf{5 7 0}}(x \pm s, n=3)$ \\
\hline Control & $1.236 \pm 0.117$ & - & 6.25 & $0.913 \pm 0.017^{\dagger}$ \\
0.78 & $1.080 \pm 0.049$ & 12.6 & 12.5 & $0.865 \pm 0.025^{\dagger}$ \\
1.56 & $0.993 \pm 0.054^{\star}$ & 19.7 & 25 & $0.804 \pm 0.056^{\dagger}$ \\
3.13 & $0.942 \pm 0.069^{\star}$ & 23.8 & 50 & $0.701 \pm 0.031^{\dagger}$ \\
\hline
\end{tabular}

${ }^{\star} P<0.05$ versus control; ${ }^{\dagger} P<0.01$ versus control; $\mathrm{IR} \%$, inhibition rate (\%).

\section{Intradermal tumor angiogenesis}

To assess the effect of the immune response on tumor-associated angiogenesis induced by anti-GRP DNA vaccine pCR3.1-VS-HSP65-TP-GRP6-M2, RM-1 tumor cells were implanted intradermally at two sites in the abdominal region. Three groups of mice were immunized with saline, vaccine control pCR3.1-VS-HSP65-TP-M2, or anti-GRP DNA vaccine pCR3.1-VS-HSP65-TP-GRP6-M2 respectively, as described earlier. As shown in Fig. 6, tumor cells implanted intradermally were found to induce significant angiogenesis when the intradermal tumor grows up to $5 \mathrm{~mm}$ in diameter. The total number of blood vessels around each implant site from mice immunized with anti-GRP DNA vaccine pCR3.1-VS-HSP65-TP-GRP6-M2 was significantly lower than blood vessels from saline $(21 \pm 7$ vs $56 \pm 9 ; \quad P<0.001)$ and mice immunized with vaccine control pCR3.1-VS-HSP65-TP-M2 (21 \pm 7 vs $60 \pm 9 ; P<0.001)$.

\section{Histological examination of tumor sample sections by PAS staining}

Sections of intradermal tumors were stained with PAS base staining and viewed on the microscope. As shown in Fig. 7, tumor sections from the vaccine control group or saline group have been detected with the presence of PAS-positive loops which are known to be a marker of aggressive tumors. In contrast, these PASpositive loops were highly diminished in the tumor sections from pCR3.1-VS-HSP65-TP-GRP6-M2 immunized group or even absent in some sections.

\section{Discussion}

Over the past 20 years, abundant evidence has been collected to suggest that GRP and its receptors play an important role in the development of a variety of cancers (Patel et al. 2006). These observations have inspired researchers to find a suitable approach to treat cancers by taking advantage of blocking the GRP to GRPR signal pathway. Many kinds of GRPR antagonist, such as peptide antagonists RC-3095 and RC-3940II (Miyazaki et al. 1998) as well as non-peptide antagonists PD176252 and PD168368 (Moody et al. 2000, 2003), have been developed to inhibit the growth of various cancers. Other works have shown that a mouse monoclonal antibody 2A11 against GRP is able to block proliferation of small cell lung cancer (SCLC) cell lines (Chaudhry et al. 1999). In addition, such cytotoxic peptide conjugates as doxorubicin-bombesin conjugates (Nagy et al. 1997, Szepeshazi et al. 2003) and camptothecin-bombesin conjugates (Moody et al. 2004) have also shown impressive antitumor activity. In the current investigation, the strategy of GRP

Table 3 Suppression on the proliferation of RM-1 cells with immune sera

\begin{tabular}{|c|c|c|c|c|}
\hline Group & $\boldsymbol{A}_{570}{ }^{\mathrm{a}}(x \pm s, n=3)$ & IR\% & $\boldsymbol{A}_{570}{ }^{\mathrm{b}}(x \pm s, n=3)$ & IR\% \\
\hline Control & $1.174 \pm 0.058$ & - & $1.166 \pm 0.055$ & - \\
\hline Saline & $1.187 \pm 0.041$ & -1.2 & $1.162 \pm 0.069$ & 0.4 \\
\hline pCR3.1-VS-HSP65-TP-M2 & $1.170 \pm 0.046$ & -0.3 & $1.151 \pm 0.087$ & 1.3 \\
\hline pCR3.1-VS-HSP65-GRP6 & $1.160 \pm 0.035$ & 0.6 & $1.118 \pm 0.083$ & 4.1 \\
\hline pCR3.1-VS-HSP65-TP-GRP6 & $1.133 \pm 0.067$ & 2.9 & $1.048 \pm 0.087$ & 10.1 \\
\hline pCR3.1-VS-HSP65-TP-GRP6-M1 & $1.167 \pm 0.046$ & -0.1 & $1.108 \pm 0.084$ & 5.0 \\
\hline pCR3.1-VS-HSP65-TP-GRP6-M2 & $0.918 \pm 0.062^{*}$ & 21.3 & $0.795 \pm 0.054^{*}$ & 31.8 \\
\hline pCR3.1-VS-HSP65-TP-GRP6-M3 & $1.152 \pm 0.053$ & 1.2 & $1.105 \pm 0.086$ & 5.8 \\
\hline
\end{tabular}

${ }^{\star} P<0.01$ versus control; IR\%, inhibition rate $(\%)$.

${ }^{\mathrm{a}} 10 \%$ of sera in culture medium (10\% of PBS in control culture medium).

${ }^{\mathrm{b}} 50 \%$ of sera in culture medium (50\% of PBS in control culture medium). 
Table 4 Average tumor weight of tumors from immunized mice

\begin{tabular}{lcc}
\hline Group & $\begin{array}{c}\text { Tumor } \\
\text { weight/g }\end{array}$ & $\begin{array}{c}\text { Inhibitory } \\
\text { rate/\% }\end{array}$ \\
\hline Saline & $2.025 \pm 0.766$ & - \\
pCR3.1-VS-HSP65-TP-M2 & $2.018 \pm 0.492$ & 0.31 \\
pCR3.1-VS-HSP65-TP-GRP6 & $1.652 \pm 0.388$ & 18.41 \\
pCR3.1-VS-HSP65-TP-GRP6-M & $1.833 \pm 0.486$ & 9.47 \\
pCR3.1-VS-HSP65-TP-GRP6-M2 & $0.748 \pm 0.440^{*}$ & 63.06 \\
\hline
\end{tabular}

${ }^{\star} P<0.01$ versus saline.

deprivation by anti-GRP DNA vaccines has been applied and proved to be an appealing approach for cancer treatment. This vaccine-based therapy has substantial advantages over these previously described cancer chemotherapies: it is less toxic and allows longterm treatments while significantly reducing the cost involved in cancer treatment.

The mechanisms underlying the ability of the anti-GRP DNA vaccine to inhibit the proliferation of RM-1 cells in vivo have yet to be elucidated. It is clear that the humoral immune response has been elicited by vaccination of DNA vaccine with a high titer of GRP-specific Abs detected. This phenomenon suggests that GRP-specific Abs neutralize the self-peptide GRP and lower the concentration of GRP around the tumor, the activation of GRPR may therefore be interrupted and the successive signalling pathways can be blocked. Very recently, Garcia et al. (2008) reported the humoral immune response of patients enrolled in a randomized phase II clinical trial using epidermal growth factor (EGF) vaccination blocked the binding of EGF to its receptor (EGFR), which slowed down tumor cell proliferation and correlated with survival in vaccinated non-small-cell lung cancer (NSCLC) patients. The strategy of exploiting anti-EGF autoantibodies to block the EGF/EGFR autocrine loop reduces the growth rate of EGF-dependent tumors, which can also support the function of anti-GRP autoantibodies in reducing the growth rate of GRP-dependent tumors. Both GRP and EGF deprivation therapy can be classified into therapeutic interventions aiming to deprive cancer cells of their required hormone or growth factor, as reviewed in Gonzalez \& Lage (2007). Clinical trials have been initiated using immunization with human chorionic gonadotrophin, gastrin, LHRH/ GnRH, and EGF. Preliminary data already show that both the antibody titers and the decrease in the hormone level are related to survival. These vaccines are not meant to destroy the tumor by inducing immune effector mechanisms, but to re-set the cell proliferation rate below tumor cell death rate, resulting in inhibition of further tumor cell growth.
Although the target sequence chosen in this study is a $\mathrm{B}$ cell epitope, the potential $\mathrm{T}$ cell epitope in this region of GRP might also exist. With this hypothesis, the $T$ cell-mediated immune responses induced by antiGRP vaccines have been tested in vitro as described elsewhere, for example, Jin et al. (2008). Based on our unpublished results, splenocytes isolated from mice immunized with pCR3.1-VS-HSP65-TP-GRP6-M2 induced strong $\mathrm{T}$ cell proliferation after stimulation with ConA, but not with chemo-synthesized peptide $\mathrm{GRP}_{18-27}$. In addition, the supernatants of splenocyte culture were used for detection of interferon- $\gamma$ (IFN- $\gamma$ ) and interleukin-10 (IL-10) by ELISPOT technique. As expected, splenocytes from immunized mice did not generate IFN- $\gamma$ or IL-10 cytokines after stimulation with peptide $\mathrm{GRP}_{18-27}$. All these results definitely showed that a $\mathrm{T}$ cell-mediated immune response targeting GRP was not induced after immunization with anti-GRP DNA vaccine. The target sequence chosen in this study is merely a B cell epitope.
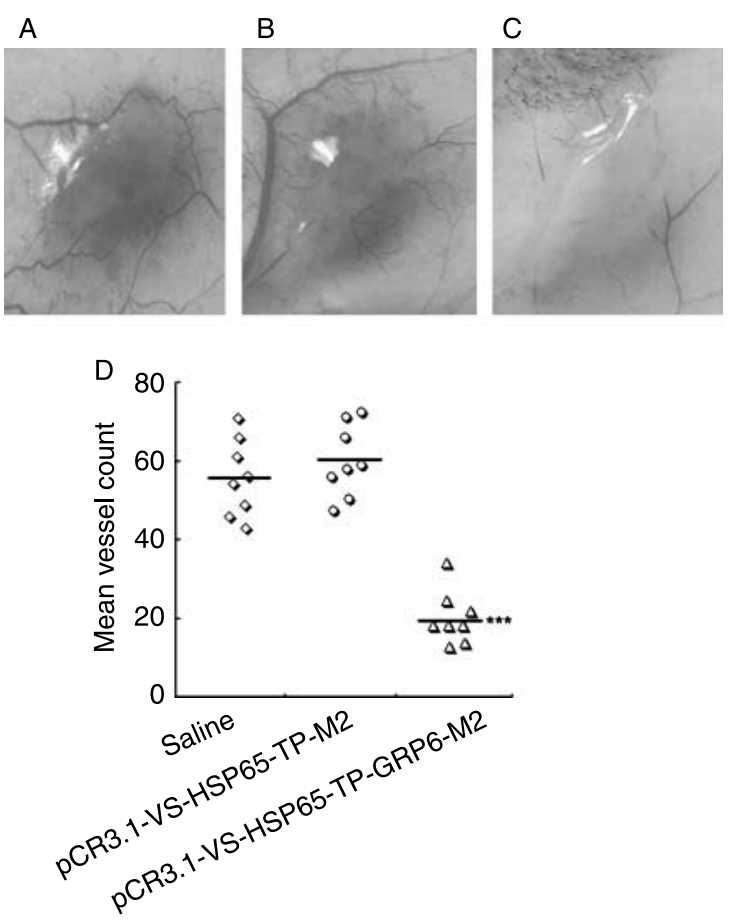

Figure 6 Effects of anti-GRP vaccine on the angiogenesis of intradermal tumors. Light microscopical picture of RM-1 tumor cells implanted intradermally in the anterior abdominal wall and the development of new blood vessels. Tumor-associated angiogenesis (2/mouse, 4 mice/group) in mice injected with saline (A) and pCR3.1-VS-HSP65-TP-M2 control vaccine

(B) appeared to be significantly higher than in mice immunized with the anti-GRP vaccine pCR3.1-VS-HSP65-TP-GRP6-M2

(C). Representative images were taken at $10 \times$ objective.

(D) The total number of blood vessels (major vessels and branching points) was determined within the precise $1 \mathrm{~cm}^{2}$ area around each implant site. ${ }^{\star \star \star} P<0.001$. 
A

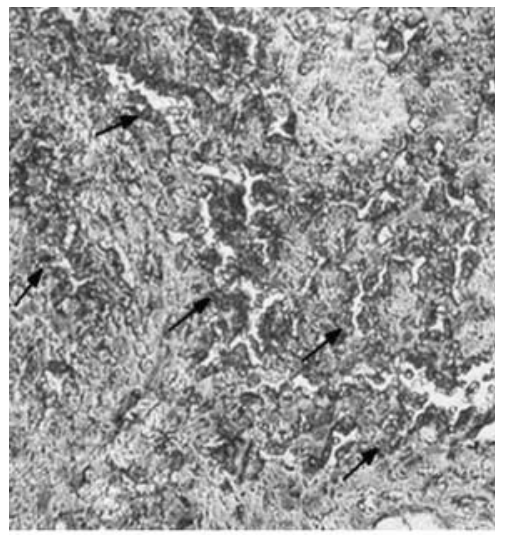

B

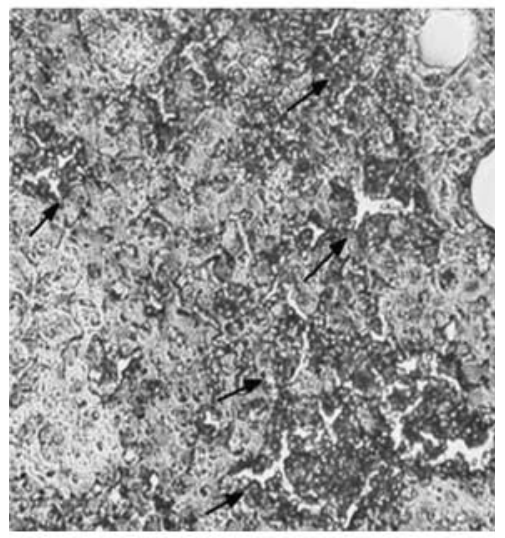

C

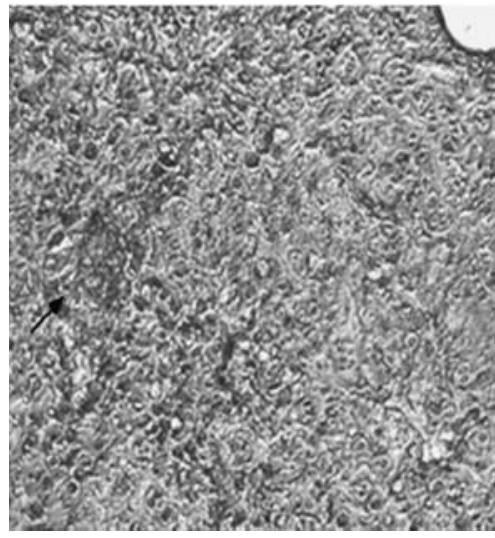

Figure 7 Light microscopic view of PAS-hematoxylin-stained tissue sections of intradermal tumors. Tumor sections from both saline group (A) and vaccine control group pCR3.1-VS-HSP65TP-M2 (B) have been detected with the presence of PASpositive loops within which red blood cells were identified. These PAS-positive loops were highly diminished in the tumor sections from pCR3.1-VS-HSP65-TP-GRP6-M2 immunized group (C). Arrows demonstrate PAS-positive loops with red blood cells.

GRP is a self-peptide, and appears to be very effective at establishing immunological tolerance. There are hardly any reports of circulating autoantibodies to hormone/growth factors being detected in humans. Thus, the production of sufficient and sustained levels of GRP-specific antibody should require a special strategy to vaccine design, especially for subunit DNA vaccines with relatively weak immunogenicity. In the current DNA vaccine construction, human $\mathrm{GRP}_{18-27}$ was chosen as the targeting $B$ cell epitope based on reports that the 7-amino-acid C-terminal sequence of Bombesin-like peptides (BLPs) is required for immunogenicity and bioactivity (Papac et al. 1994). In order to optimize its immunogenicity, the following strategies have been exploited: 1) $\mathrm{GRP}_{18-27}$ epitope was tandemly repeated six times to enhance the humoral immune response. Our previous study has established that increased immunogenicity as well as anti-tumor effects of immunogens containing tandemly repeated B cell epitopes is associated with the increased copy number of the target sequence (Yankai et al. 2006); 2) HSP65 served as a suitable and safe carrier molecule for delivering $\mathrm{B}$ cell epitopes to the immune system; 3) eight $5^{\prime}$-GACGTT-3' CpG motifs which can activate antigen presenting cells through Toll-like receptors (Shah et al. 2003) have been constructed into the plasmid vector as an adjuvant; and 4) synthetic peptides representing helper T-lymphocyte epitopes such as those encoded by tetanus toxoid fragment 830-844, pan HLA-DR-binding epitope, or mHSP70 fragment 407-426, have been incorporated as immunoadjuvants. Our results showed that two copies of mHSP70 $407-426$ epitope downstream of GRP6 not only significantly boosted the anti-GRP Abs in sera, but also markedly enhanced the relative avidity of anti-GRP Abs.

Studies have already shown the linkage of antigens to both mHSP70 and the C-terminal portion of mHSP70 (359-610) to represent a potential approach to increase the potency of DNA vaccines (Chen et al. 2000, Li et al. 2006). We have now introduced the peptide $\mathrm{HSP}_{407-426}$, identified as a major epitope stimulating tumor necrosis factor- $\alpha$, IL-12, and CCL-5 in monocytes and dendritic cells in mHSP70 (Wang et al. 2005), into anti-GRP DNA vaccines as immunoadjuvants. Our data also showed a highly Th1-polarized immune responses in mice when HSP70 407-426 was used as an immunoadjuvant, which might be more beneficial in cancer treatment. Interestingly, plasmids encoding for $2 \mathrm{HSP} 70_{407-426}$, but not the one for $3 \mathrm{HSP}_{407-426}$ showed stronger immune stimulatory potential as well as impressive antitumor activity. The reasons for this phenomenon could be that: 1) although mer-epitope effects can induce stronger immunogenicity of the epitope, as the number of the epitope copies increases, the 
immunogenicity of this epitope becomes stronger, and this effect could then meet a crucial point in which the number is still increasing while the immunogenicity decreases (based on unpublished data from our lab). Thus, it is not the more repeated copies of epitope, but rather the moderate one which can induce the strongest immune responses; or 2) $\mathrm{HSP}_{407-426}$ epitope in these plasmids is the T-helper epitope, and the leading role should be played by the GRP epitope. Too many repeated copies of HSP70 $407-426$ will decrease the immune responses to GRP. The exact mechanism under this phenomenon is now under detailed investigation in our lab. However, the current results have shown that $2 \mathrm{HSP}_{407-426}$ is an efficient molecular adjuvant for developing self-epitope vaccines.

GRP has been reported to stimulate pro-angiogenic gene expression as well as the expression of various angiogenic markers including platelet-endothelial cell adhesion molecule (PECAM-1), vascular endothelial growth factor (VEGF) and phosphorylated-Akt levels (Kang et al. 2007). Moreover, GRP or GRPR silencing has been reported to significantly suppress tumor progression and vascularization (Cornelio et al. 2007). In this study, the ability of anti-angiogenesis by anti-GRP DNA vaccine has been investigated in an intradermal tumor model. Our results demonstrate the immune responses induced by pCR3.1-VS-HSP65TP-GRP6-M2 significantly reduced the tumor-associated angiogenesis and vascularization of RM-1 solid tumors. In addition, histological examination of intradermal tumors showed the PAS-positive loops were attenuated by GRP-immune arrest, indicating that intratumor microhemorrhages and tumor cell nutrition (which can be represented by the presence of PASpositive loops (Lee et al. 2002, Clarijs et al. 2003)) were highly diminished. The anti-angiogenesis effects of plasmid pCR3.1-VS-HSP65-TP-GRP6-M2 may further hamper tumor progression, contributing to the inhibition of tumor growth in vivo.

In conclusion, we constructed a novel anti-GRP DNA vaccine with a high immunogenicity by the introduction of a new efficient molecular adjuvant $2 \mathrm{HSP} \mathrm{0}_{407-426}$. The highly immunogenic and potent anti-tumorigenic activities of the anti-GRP DNA vaccine offer a novel immunotherapeutic approach in the treatment of the GRP-dependent tumors and their complications.

\section{Declaration of interest}

There is no conflict of interest that would prejudice the impartiality of this scientific work.

\section{Funding}

This work was supported by China National Natural Science Fund Committee (Grants \#30672464, \#30701023, \#30872393, and \#30772570) and Jiangsu Natural Science Fund Committee (Grants \#BK 2007170 and BG2001011).

\section{References}

Agadjanyan MG, Ghochikyan A, Petrushina I, Vasilevko V, Movsesyan N, Mkrtichyan M, Saing T \& Cribbs DH 2005 Prototype Alzheimer's disease vaccine using the immunodominant B cell epitope from beta-amyloid and promiscuous T cell epitope pan HLA DR-binding peptide. Journal of Immunology 174 1580-1586.

Alexander J, del Guercio MF, Maewal A, Qiao L, Fikes J, Chesnut RW, Paulson J, Bundle DR, DeFrees S \& Sette A 2000 Linear PADRE T helper epitope and carbohydrate B cell epitope conjugates induce specific high titer IgG antibody responses. Journal of Immunology 164 1625-1633.

Biragyn A, Tani K, Grimm MC, Weeks S \& Kwak LW 1999 Genetic fusion of chemokines to a self tumor antigen induces protective, T-cell dependent antitumor immunity. Nature Biotechnology 17 253-258.

Calarota SA \& Weiner DB 2004 Enhancement of human immunodeficiency virus type 1-DNA vaccine potency through incorporation of T-helper 1 molecular adjuvants. Immunological Reviews 199 84-99.

Chaudhry A, Carrasquillo JA, Avis IL, Shuke N, Reynolds JC, Bartholomew R, Larson SM, Cuttitta F, Johnson BE \& Mulshine JL 1999 Phase I and imaging trial of a monoclonal antibody directed against gastrin-releasing peptide in patients with lung cancer. Clinical Cancer Research 5 3385-3393.

Chen CH, Wang TL, Hung CF, Yang Y, Young RA, Pardoll DM \& Wu TC 2000 Enhancement of DNA vaccine potency by linkage of antigen gene to an HSP70 gene. Cancer Research 60 1035-1042.

Clarijs R, Schalkwijk L, Ruiter DJ \& de Waal RM 2003 EMAP-II expression is associated with macrophage accumulation in primary uveal melanoma. Investigative Ophthalmology \& Visual Science 44 1801-1806.

Cornelio DB, Roesler R \& Schwartsmann G 2007 Gastrin-releasing peptide receptor as a molecular target in experimental anticancer therapy. Annals of Oncology 18 1457-1466.

Cusi MG, Terrosi C, Savellini GG, Di Genova G, Zurbriggen R \& Correale P 2004 Efficient delivery of DNA to dendritic cells mediated by influenza virosomes. Vaccine 22 735-739.

Donnelly JJ, Ulmer JB, Shiver JW \& Liu MA 1997 DNA vaccines. Annual Review of Immunology 15 617-648. 
Garcia B, Neninger E, de la Torre A, Leonard I, Martinez R, Viada C, Gonzalez G, Mazorra Z, Lage A \& Crombet T 2008 Effective inhibition of the epidermal growth factor/epidermal growth factor receptor binding by anti-epidermal growth factor antibodies is related to better survival in advanced non-small-cell lung cancer patients treated with the epidermal growth factor cancer vaccine. Clinical Cancer Research 14 840-846.

Gonzalez G \& Lage A 2007 Cancer vaccines for hormone/ growth factor immune deprivation: a feasible approach for cancer treatment. Current Cancer Drug Targets 7 229-241.

Greenland JR \& Letvin NL 2007 Chemical adjuvants for plasmid DNA vaccines. Vaccine 25 3731-3741.

Guojun W, Wei G, Kedong O, Yi H, Yanfei X, Qingmei C, Yankai Z, Jie W, Hao F, Taiming L et al. 2008 A novel vaccine targeting gastrin-releasing peptide: efficient inhibition of breast cancer growth in vivo. Endocrine-Related Cancer 15 149-159.

Hung CF, Cheng WF, Chai CY, Hsu KF, He L, Ling M \& Wu TC 2001 Improving vaccine potency through intercellular spreading and enhanced MHC class I presentation of antigen. Journal of Immunology 166 5733-5740.

Jin L, Zhu A, Wang Y, Chen Q, Xiong Q, Li J, Sun Y, Li T, Cao R, Wu J et al. 2008 A Th1-recognized peptide P277, when tandemly repeated, enhances a Th2 immune response toward effective vaccines against autoimmune diabetes in nonobese diabetic mice. Journal of Immunology 180 58-63.

Kang J, Ishola TA, Baregamian N, Mourot JM, Rychahou PG, Evers BM \& Chung DH 2007 Bombesin induces angiogenesis and neuroblastoma growth. Cancer Letters 253 273-281.

King CA, Spellerberg MB, Zhu D, Rice J, Sahota SS, Thompsett AR, Hamblin TJ, Radl J \& Stevenson FK 1998 DNA vaccines with single-chain Fv fused to fragment $\mathrm{C}$ of tetanus toxin induce protective immunity against lymphoma and myeloma. Nature Medicine 4 1281-1286.

Klinman DM, Yamshchikov G \& Ishigatsubo Y 1997 Contribution of $\mathrm{CpG}$ motifs to the immunogenicity of DNA vaccines. Journal of Immunology $\mathbf{1 5 8}$ 3635-3639.

Kreisle RA \& Ershler WB 1988 Investigation of tumor angiogenesis in an id mouse model: role of host-tumor interactions. Journal of the National Cancer Institute $\mathbf{8 0}$ 849-854.

Kumar A, Arora R, Kaur P, Chauhan VS \& Sharma P 1992 "Universal" T helper cell determinants enhance immunogenicity of a Plasmodium falciparum merozoite surface antigen peptide. Journal of Immunology 148 1499-1505.

Lee YJ, Nagai N, Siar CH, Nakano K, Nagatsuka H, Tsujigiwa H, Roan CH \& Gunduz M 2002 Angioarchitecture of primary oral malignant melanomas. Journal of Histochemistry and Cytochemistry $\mathbf{5 0}$ 1555-1562.
Li X, Yang X, Li L, Liu H \& Liu J 2006 A truncated C-terminal fragment of Mycobacterium tuberculosis HSP70 gene enhanced potency of HBV DNA vaccine. Vaccine 24 3321-3331.

Miyazaki M, Lamharzi N, Schally AV, Halmos G, Szepeshazi K, Groot K \& Cai RZ 1998 Inhibition of growth of MDA-MB-231 human breast cancer xenografts in nude mice by bombesin/gastrin-releasing peptide (GRP) antagonists RC-3940-II and RC-3095. European Journal of Cancer 34 710-717.

Moody TW, Jensen RT, Garcia L \& Leyton J 2000 Nonpeptide neuromedin B receptor antagonists inhibit the proliferation of C6 cells. European Journal of Pharmacology 409 133-142.

Moody TW, Leyton J, Garcia-Marin L \& Jensen RT 2003 Nonpeptide gastrin releasing peptide receptor antagonists inhibit the proliferation of lung cancer cells. European Journal of Pharmacology 474 21-29.

Moody TW, Mantey SA, Pradhan TK, Schumann M, Nakagawa T, Martinez A, Fuselier J, Coy DH \& Jensen RT 2004 Development of high affinity camptothecin-bombesin conjugates that have targeted cytotoxicity for bombesin receptor-containing tumor cells. Journal of Biological Chemistry 279 23580-23589.

Nagy A, Armatis P, Cai RZ, Szepeshazi K, Halmos G \& Schally AV 1997 Design, synthesis, and in vitro evaluation of cytotoxic analogs of bombesin-like peptides containing doxorubicin or its intensely potent derivative, 2-pyrrolinodoxorubicin. PNAS 94 652-656.

Papac DI, Hoyes J \& Tomer KB 1994 Epitope mapping of the gastrin-releasing peptide/anti-bombesin monoclonal antibody complex by proteolysis followed by matrixassisted laser desorption ionization mass spectrometry. Protein Science 3 1485-1492.

Patel O, Shulkes A \& Baldwin GS 2006 Gastrin-releasing peptide and cancer. Biochimica et Biophysica Acta 1766 23-41.

Perraut R, Lussow AR, Gavoille S, Garraud O, Matile H, Tougne C, van Embden J, van der Zee R, Lambert PH, Gysin J et al. 1993 Successful primate immunization with peptides conjugated to purified protein derivative or mycobacterial heat shock proteins in the absence of adjuvants. Clinical and Experimental Immunology 93 382-386.

Perschinka H, Mayr M, Millonig G, Mayerl C, van der Zee R, Morrison SG, Morrison RP, Xu Q \& Wick G 2003 Cross-reactive B-cell epitopes of microbial and human heat shock protein 60/65 in atherosclerosis. Arteriosclerosis, Thrombosis, and Vascular Biology 23 1060-1065.

Pullen GR, Fitzgerald MG \& Hosking CS 1986 Antibody avidity determination by ELISA using thiocyanate elution. Journal of Immunological Methods 86 83-87. 
Shah JA, Darrah PA, Ambrozak DR, Turon TN, Mendez S, Kirman J, Wu CY, Glaichenhaus N \& Seder RA 2003 Dendritic cells are responsible for the capacity of $\mathrm{CpG}$ oligodeoxynucleotides to act as an adjuvant for protective vaccine immunity against Leishmania major in mice. Journal of Experimental Medicine 198 281-291.

Szepeshazi K, Schally AV, Nagy A, Wagner BW, Bajo AM \& Halmos G 2003 Preclinical evaluation of therapeutic effects of targeted cytotoxic analogs of somatostatin and bombesin on human gastric carcinomas. Cancer $\mathbf{9 8}$ 1401-1410.

Wang Y, Kelly CG, Singh M, McGowan EG, Carrara AS, Bergmeier LA \& Lehner T 2002 Stimulation of Th1-polarizing cytokines, $\mathrm{C}-\mathrm{C}$ chemokines, maturation of dendritic cells, and adjuvant function by the peptide binding fragment of heat shock protein 70. Journal of Immunology 169 2422-2429.

Wang Y, Whittall T, McGowan E, Younson J, Kelly C, Bergmeier LA, Singh M \& Lehner T 2005 Identification of stimulating and inhibitory epitopes within the heat shock protein 70 molecule that modulate cytokine production and maturation of dendritic cells. Journal of Immunology 174 3306-3316.

Xiangping Q, Dongmei X \& Christian WH 2003 Biologic relevance of mammalian bombesin-like peptides and their receptors in human malignancies. Current Opinion in Endocrinology and Diabetes 1011.

Xu J, Zhu Z, Wu J, Liu W, Shen X, Zhang Y, Hu Z, Zhu D, Roque RS \& Liu J 2008 Immunization with a recombinant $\mathrm{GnRH}$ vaccine conjugated to heat shock protein 65 inhibits tumor growth in orthotopic prostate cancer mouse model. Cancer Letters 259 240-250.

Yankai Z, Rong Y, Yi H, Wentao L, Rongyue C, Ming Y, Taiming L, Jingjing L \& Jie W 2006 Ten tandem repeats of beta-hCG 109-118 enhance immunogenicity and antitumor effects of beta-hCG C-terminal peptide carried by mycobacterial heat-shock protein HSP65. Biochemical and Biophysical Research Communications 345 1365-1371. 